\title{
Assessing the Impacts of High Speed Rail Development in China's Yangtze River Delta Megaregion
}

\author{
Xueming Chen \\ L. Douglas Wilder School of Government and Public Affairs, Virginia Commonwealth University, \\ Richmond, USA \\ Email: xchen2@vcu.edu
}

Received December 5, 2012; revised January 7, 2013; accepted January 16, 2013

Copyright (C) 2013 Xueming Chen. This is an open access article distributed under the Creative Commons Attribution License, which permits unrestricted use, distribution, and reproduction in any medium, provided the original work is properly cited.

\begin{abstract}
This paper assesses the impacts of high speed rail (HSR) development in the Yangtze River Delta (YRD) Megaregion, China. After giving an introduction and conducting a literature review, the paper proposes a pole-axis-network system (PANS) model guiding the entire study. On the one hand, the HSR projects in the YRD Megaregion are expected to generate significant efficiency-related transportation and non-transportation benefits. As a result, the spillover effects from Shanghai and other major cities (poles) will greatly promote the urban and regional developments along the major HSR corridors (axes), and the entire megaregion will become more integrated economically, socially, and culturally. But, on the other hand, the HSR projects will also create serious social and geographic inequity issues, which need to be addressed as soon as possible in a proper way. This empirical study confirms the PANS model proposed.
\end{abstract}

Keywords: High Speed Rail; China; Yangtze River Delta Megaregion; Impacts

\section{Introduction}

China is building the world's largest high speed rail (HSR) network, which is expected to generate significant though uneven impacts on its mobility, accessibility, socioeconomic development, and others, especially at megaregional levels. According to the "Mid-to-Long Term Railway Network Plan" approved by the State Council in 2004 , China will have a total of $100,000 \mathrm{~km}$ (revised to $120,000 \mathrm{~km}$ in 2008) of railroads by the year 2020, of which $12,000 \mathrm{~km}$ (revised to $16,000 \mathrm{~km}$ in 2008) are high speed rail lines with an average operating speed of $200 \mathrm{~km} / \mathrm{h}$ and faster, linking all provincial capital cities and those cities with more than 500,000 population [1]. For reference, as of early 2008, there were only approximately $10,000 \mathrm{~km}$ of high speed rail lines in operation in the entire world, including about $2000 \mathrm{~km}$ in Japan and about $1900 \mathrm{~km}$ in France [2].

Of all Chinese megaregions, the Yangtze River Delta (YRD) Megaregion (1\% of national land) occupies the most prominent position in terms of its economic strength (20\% of national gross domestic products) and population size ( $6 \%$ of national population). This megaregion is expected to possess about a dozen of existing and proposed rail lines, including trunk passenger dedicated lines (PDLs), intercity HSR lines, and other conventional rail lines. HSR has its relative speed advantage over highway and aviation for the distance between 100 miles and 500 miles, which, to a large extent, matches a typical megaregion's geographic extent in the world. Because of this reason, HSR network directly impacts the megaregion-wide development, and vice versa.

Following this introduction, the paper contains additional six sections. Section 2 reviews the most important and relevant literatures. Section 3 presents a research methodology guiding the entire study. Section 4 describes the HSR lines traversing this megaregion. Section 5 assesses the HSR-generated transportation and non-transportation impacts from the efficiency's standpoints. Section 6 examines the geographic equity issues associated with the HSR developments in this region. Finally, Section 7 summarizes research findings and draws conclusions.

\section{Literature Review}

Japan and Europe are the leading country and continent to develop HSR technology. Both Japanese and European HSR development experience indicates that HSR has the indisputable transportation efficiency impacts. However, its transportation equity and socioeconomic impacts are more controversial and elusive [3]. 
In terms of its transportation efficiency, HSR can directly achieve time savings due to its higher operating speeds. For example, the Tokaido Shinkansen began service on October 1, 1964, in time for the Tokyo Olympics. The conventional Limited Express service took six hours and 40 minutes to travel from Tokyo to Osaka, but the Shinkansen made the trip in just four hours in 1964, shortened to three hours and ten minutes in 1965, further down to about two hours at present.

Reference [4] finds that HSR directly contributes to a favorable modal shift towards HSR train, based on his study on the French Train Grande Vitesse (TGV) and Spanish Alta Velocidad Española (AVE) operating performance. From Table 1, it can be seen that HSR train and aircraft are direct competitors.

In spite of its obvious transportation efficiency benefits, HSR typically will not benefit different regions equally. Reference [6] evaluates the impact of the future European high speed train network on accessibility by reducing travel time between places and modifying their relative locations. His accessibility indicators consist of calculating a weighted average of the travel times separating each node with respect to the chief economic activity centers, and economic potential model. He found that high speed train will bring the peripheral regions closer to the central ones, but will also increase imbalances between the main cities and their hinterlands. Reference [7] also analyzes the accessibility impact of the Madrid-Barcelona-French border high speed line, which finds that at the national level, the new line will lead to an increase in inequality in the distribution of accessibility, for the cities, which have greatest increases in accessibility, are already highly accessible in the "without the new line scenario".

Reference [8] conducts the entire Chinese HSR accessibility study. Assuming with HSR and without HSR scenarios, [8] calculates the weighted average travel time by region, HSR access, and city size, which finds that: cities with HSR stations receive higher accessibility benefit than non-HSR cities; and larger cities receive more HSR benefits than smaller cities.

The HSR's socioeconomic impacts are more disputable, though. For example, the Japanese Shinkansen has generated profound impacts on its service sector development. Between 1981 and 1985, the number of em- ployees in information, survey and advertising industries increased by $125 \%$ in the areas with both express highway and high speed rail, but only by $63 \%$ in the areas with express highway only [9]. In addition, the regions served by the Shinkansen achieved higher population and employment growth rates than those without direct Shinkansen services. However, it should be cautioned that there may be other factors prevailing in these regions as well that could support and affect such an impact, and it is thus unclear if the Shinkansen indeed led to the increase in growth rates or if the Shinkansen was merely constructed in regions where higher growth rates had already existed [10].

Reference [11] acknowledges that spatial dynamics are often associated with the development of physical and social networks in which the nodes (e.g. cities and towns) profit from agglomeration advantages and scale effects. This means that only those cities and places located in the immediate vicinity of HSR stations typically reap benefits. [12] argues that a TGV link is closer to that of an airliner than that of a traditional train when one considers the lengths of journeys from city to city, the seating capacity (and therefore the commercial objectives regarding rate of utilization) and the means of operation (city A-city B). The result is that the structural effects are centered on urban poles and their immediate environs. Because of $\mathrm{TGV}$, Lille, which is the largest industrial city in northern France, has been transformed from an industrial city to a commercial and business-oriented city. Many tertiary sector firms have been using TGV services to travel between Lyon and Paris.

Generally speaking, positive spatial and socio-economic impacts might occur at places connected to the HSR network, yet in those places bypassed by the HSR, negative impacts usually occur because resources are reallocated and gravitated to those HSR-connected places [13]. In another paper, [14] further points out that core metropolitan areas with HSR stations may attract more people and economic activities, while other small cities remain left behind.

With regard to the relationships between rail investment and economic growth, [15] cautions that rail investments do not stimulate economic growth but influence "already-committed" growth and rarely have a significant influence on development patterns. Reference [4]

Table 1. Modal shares before and after the introduction of high speed train services.

\begin{tabular}{ccccccc}
\hline \multirow{2}{*}{ Mode } & \multicolumn{3}{c}{ TGV, Paris-Lyon Line } & \multicolumn{3}{c}{ AVE, Madrid-Seville Line } \\
\cline { 2 - 7 } & Before (1981) & After (1984) & Change & Before (1991) & After (1994) & Change \\
\hline Aircraft & $31 \%$ & $7 \%$ & $-24 \%$ & $40 \%$ & $13 \%$ & $-27 \%$ \\
HSR Train & $40 \%$ & $72 \%$ & $32 \%$ & $16 \%$ & $51 \%$ & $35 \%$ \\
Car and bus & $29 \%$ & $21 \%$ & $-8 \%$ & $44 \%$ & $36 \%$ & $-8 \%$ \\
\hline
\end{tabular}

Source: $[4,5]$. 
warns that cities with bad economies have a difficulty taking advantage of HSR, and may even suffer economic decline. Therefore, HSR is not justified solely based on economic development benefits because the benefits are not great enough. Reference [16] cogently points out that transport infrastructure investment in general acts as a complement to other more important underlying conditions (for example, economic externalities, investment factors, and political factors), which must be met if further economic development is to take place. In the meantime, the potential ability of transport infrastructure investments to produce transport benefits, such as travel time reductions, is not questioned.

Unlike aviation which only impacts a flight's origin and destination metropolises (point effects), HSR generates line effects as well. Reference [17] argues that the HSR not only can be used as a substitute for air traveling, but also can link many cities with an interregional accessibility, thus forming a functional region. In Spain, the HSR network was initially intended to strengthen the relations between distant metropolises (e.g., Madrid, Barcelona, Seville), but it is also showing its usefulness for smaller and closer cities that lie between metropolises.

In summary, there is no universally agreed-on consensus on the socioeconomic impacts of HSR development, which vary from places to places.

\section{Research Methodology}

This paper utilizes the economic potential model to quantify one of the most important transportation efficiencies: accessibility. According to [7], the economic potential is a gravity-based measure widely used in accessibility studies. According to this model, the level of opportunity (accessibility) between origin node $i$ and destination node $\mathrm{j}$ is positively related to the mass of the destination and inversely proportional to some power of the distance or travel time between both nodes. Its mathematical equation is as follows:

$$
\mathrm{P}_{\mathrm{i}}=\sum_{\mathrm{j}=1}^{\mathrm{n}} \frac{M_{\mathrm{j}}}{\mathrm{T}_{\mathrm{ij}}^{\mathrm{a}}}
$$

where $P_{i}$ is the economic potential of origin node $i$; $\alpha$ is a parameter reflecting the rate of increase of the friction of distance (distance decay. $\alpha$ is assumed to be 1 in most studies); $\mathrm{M}_{\mathrm{j}}$ is the mass of destination node $\mathrm{j}$ (e.g., gross domestic products, population); $\mathrm{T}_{\mathrm{ij}}$ is the travel time between origin node $\mathrm{i}$ and destination node $\mathrm{j}$.

With respect to quantifying geographic equity issues, this paper uses the Pole-Axis-Network System (PANS) model originally developed by Professor Dadao Lu, who is the renowned Chinese geographer. According to [18$20]$, the "pole-axis system" is one of the concepts con- cerning socio-economic spatial structure, and a theoretical model for allocation of productivity, territorial development and regional development. This concept was developed based on the "central place theory" hypothesized by German geographer Walter Christaller [21], the growth pole theory proposed by François Perroux [22], and other regional development theories [23]. In the national and regional development process, most socioeconomic elements are agglomerated at "poles (yielding agglomeration economies)" which are linked up by linear infrastructure to form an "axis". Through axes, socioeconomic factors are diffused along axes from poles to poles, thus turning nodal developments into regional developments. It should be pointed out that both poles and axes have hierarchical orders.

This paper extends this concept into the pole-axisnetwork system (PANS) concept through an empirical study. As illustrated in Figure 1, this schematic diagram assumes the existence of four tiers of cities (its sizes are symbolized by circle sizes) and three tiers of axes (Note: The Chinese province typically has four tiers of cities: provincial capital cities, provincial-ranked cities, regional cities, and county-level cities):

- Tier-1 city: the largest central city, connected to Tier1, Tier-2 and Tier-3 axes;

- Tier-2 cities: the large-sized cities, connected to Tier1 and Tier- 2 axes;

- Tier-3 cities: the medium-sized cities, connected to Tier- 2 and Tier- 3 axes; and

- Tier-4 cities: the small cities, connected to Tier-3 axes.

The PANS model proposed above can be applied to the YRD area to quantify the HSR-induced geographic inequity degrees. Since each city is connected to different tiers of axes, this paper defines the following city-level connectivity indices (CI) to compare the HSR-induced accessibilities among different cities (Note: Scale assumptions: Scale for Tier-1 Axis $=5$; Scale for Tier-2 Axis $=3$; Scale for Tier-3 Axis $=1$ ):

$$
\begin{aligned}
\text { CI } & =5 * \text { Number of Connected Tier }-1 \text { Axes } \\
& +3 * \text { Number of Connected Tier }-2 \text { Axes } \\
& +1 * \text { Number of Connected Tier }-3 \text { Axes }
\end{aligned}
$$

\section{Existing and Future Rail Lines in the YRD Megaregion}

\subsection{Inventory of Existing and Future Rail Lines}

Figure 2 and Table 2 show the alignments and characteristics of the rail lines in the YRD Megaregion, respectively. In Figure 2, the tiers of rail lines are determined based on the economic densities of the cities these rail lines traverse.

The YRD Megaregion has or will have three types of 


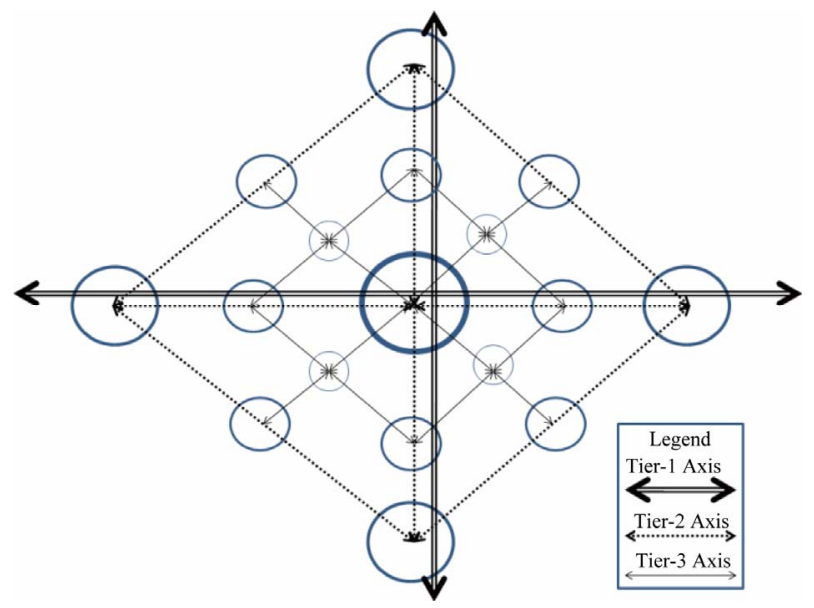

Figure 1. Pole-axis-network schematic diagram.

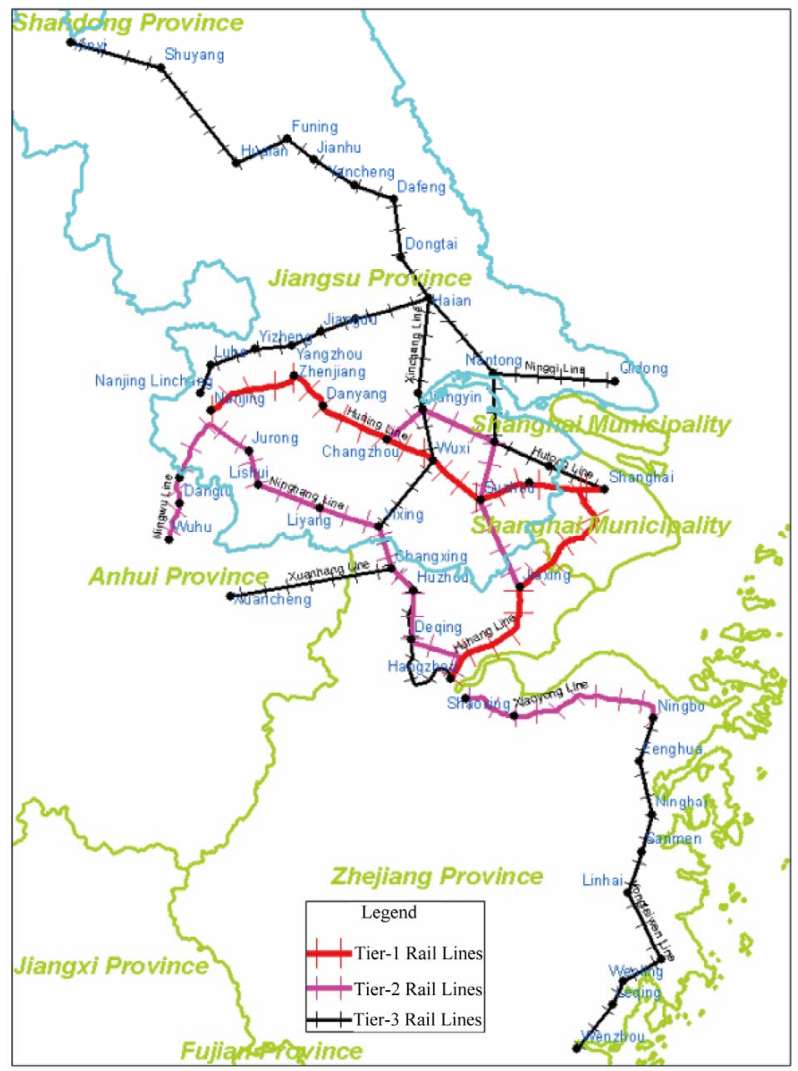

Figure 2. Alignments of the rail lines in the YRD megaregion.

rail lines, all of which have been approved for construction by the State Council through the National Development and Reform Commission:

- HSR Passenger Dedicated Lines (PDLs): intermediate- and long-distance trunk rail lines, with a design speed around $350 \mathrm{~km} / \mathrm{h}$. Examples: Beijing-Shanghai (Jinghu) PDL, and Shanghai-Kunming (Hukun) PDL;

- Intercity HSR Lines: short-distance rail lines serving neighboring cities within the megaregion, with a de- sign speed of $300-350 \mathrm{~km} / \mathrm{h}$. Examples: ShanghaiNanjing (Huning) Line, Shanghai-Hangzhou (Huhang) Line, Nanjing-Hangzhou (Ninghang) Line. This type of HSR line is a new mode lying between trunk rail lines and urban rail transportation, belonging to the category of regional rail system as defined by [24] and primarily serving daily commutes among neighboring cities. Since the travel distance is normally within $400 \mathrm{~km}$, it takes no more than 2 hours to arrive at destinations by using this mode; and

- Conventional rail lines: shared passenger/freight operations, generally with a design speed around or below $200 \mathrm{~km} / \mathrm{h}$. Examples: Nanjing-Qidong (Ningqi) Rail Line, Ningbo-Taizhou-Wenzhou (Ningtaiwen) Rail Line, Xuancheng-Hangzhou (Xuanhang) Rail Line.

Since Shanghai-Nanjing and Shanghai-Hangzhou rail lines are the most important rail lines with the highest passenger transportation densities in China and specifically serving the YRD Megaregion, they are described at length below. See Figure $\mathbf{3}$ for the rail line alignments and the major cities they link.

\subsection{Shanghai-Nanjing Rail Lines}

The Shanghai-Nanjing Corridor has three roughly paralleling rail lines: the old conventional rail line in existence since 1908; the new intercity HSR line opening on July 1, 2010 (Huning Line); and the southern Jiangsu segment of the new Beijing-Shanghai PDL opened in 2011 (Jinghu Line). The old conventional rail line will gradually be converted into a freight rail line. The latter two HSR lines will provide exclusive passenger rail services. In this way, the passenger and freight operations will be separated, thus greatly enhancing the corridor's total carrying capacity. Table 3 lists those HSR stations along the Shanghai-Nanjing Corridor.

Due to their different service types, the Jinghu Line has a much longer average station spacing (41 km/segment) than does the Huning Line (15 km/segment). The former serves large cities and through traffic, whereas the latter serves both large and small cities, and local traffic between Nanjing and Shanghai. For most cities along the corridors, the Huning Line Stations and Jinghu Line Stations typically have different geographic locations, with the former being located much closer to the downtown areas than the latter. The Jinghu Line Stations are typically the brand new stations built in the near suburban areas, with a longer access time.

\subsection{Shanghai-Hangzhou Rail Lines}

Like the Shanghai-Nanjing Corridor, the ShanghaiHangzhou Corridor also has three roughly paralleling rail lines: the old conventional rail line in existence since 
Table 2. Characteristics of the rail lines in the YRD megaregion.

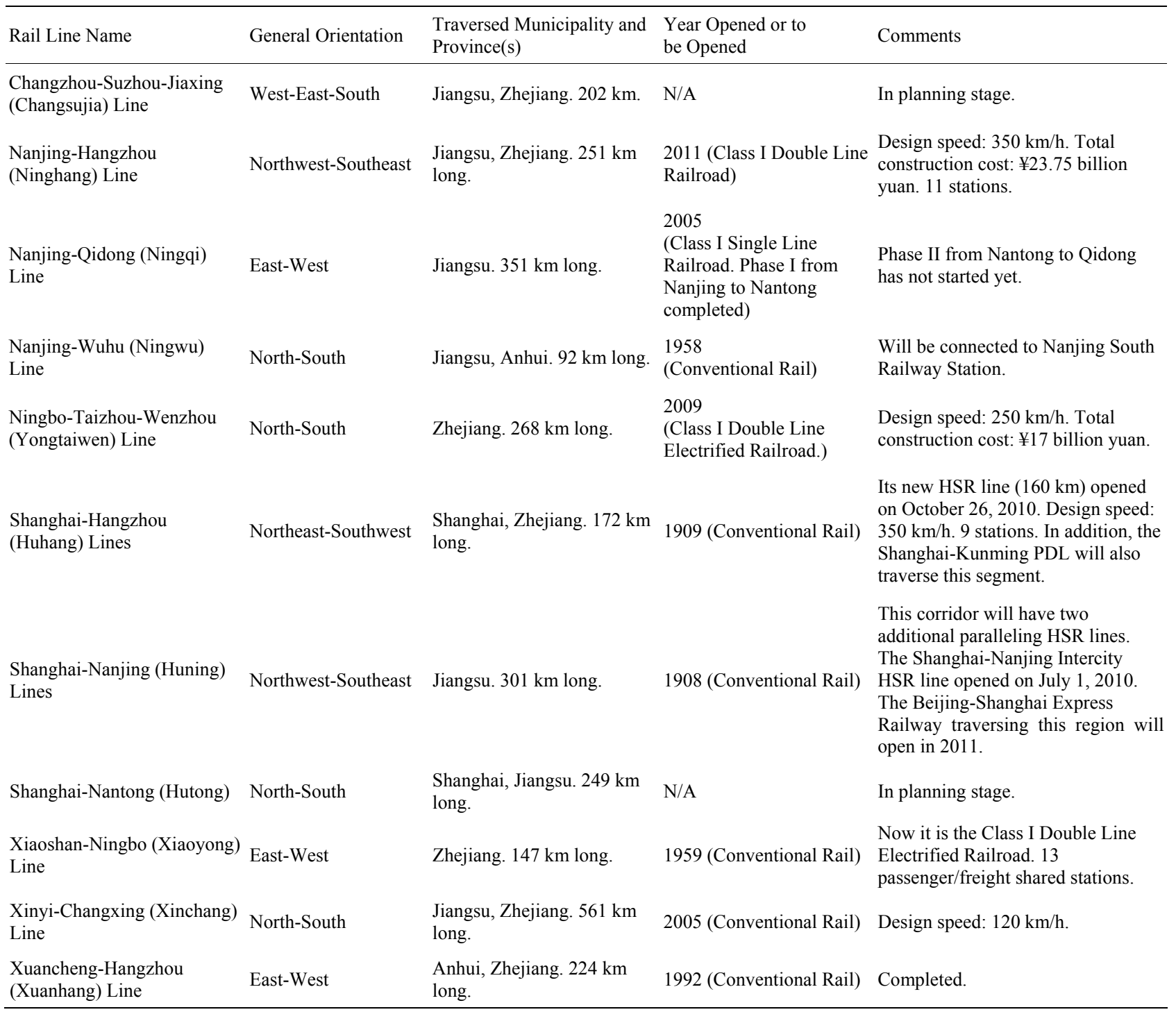

Source: $[25,26]$.

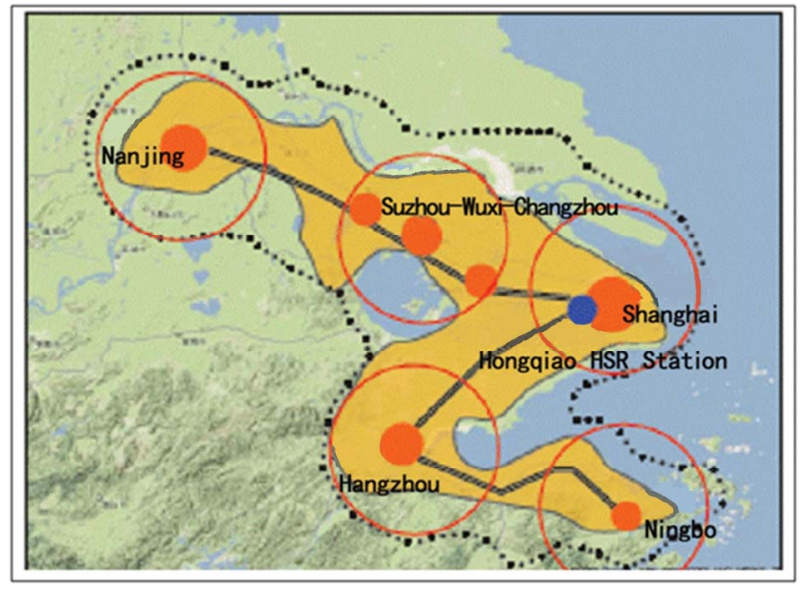

Figure 3. Shanghai-Nanjing and Shanghai-Hangzhou rail lines.
1909; the new intercity HSR line opening on October 26, 2010 (Huhang Line); and the northern Zhejiang segment of the new Shanghai-Kunming PDL scheduled to be open in 2015 (Hukun Line). The old conventional rail line will gradually be converted into a freight rail line. The latter two HSR lines will provide exclusive passenger rail services. Table 4 lists those stations located along both rail lines.

Same as in the Shanghai-Nanjing Corridor, along the Shanghai-Hangzhou Corridor, the Hukun Line has a much longer station spacing ( $79 \mathrm{~km} /$ segment) than the Huhang Line (20 km/segment) due to their different markets served. The former serves large cities and through traffic, whereas the latter serves both large and mediumsized/small cities, and local traffic between Shanghai and Hangzhou. 
Table 3. Stations along the Shanghai-Nanjing corridor.

\begin{tabular}{|c|c|c|}
\hline City/Municipality & Huning Line Stations & Jinghu Line Stations \\
\hline $\begin{array}{l}\text { Shanghai } \\
\text { Municipality }\end{array}$ & $\begin{array}{ll}\text { - } & \text { Shanghai } \\
\text { - } & \text { Shanghai West } \\
\text { - } & \text { Nanxiang North } \\
\text { Anting North }\end{array}$ & - Shanghai Hongqiao \\
\hline Suzhou City & 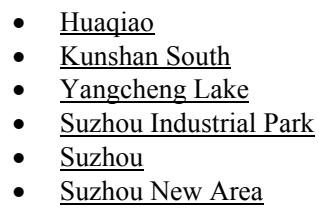 & - $\quad \underline{\text { Kunshan South }}$ \\
\hline Wuxi City & $\begin{array}{l}\text { - } \text { Wuxi New Area } \\
\text { - } \underline{\text { Wuxi }} \\
\text { Huishan }\end{array}$ & - Wuxi East \\
\hline Changzhou City & - $\frac{\text { Qishuyan }}{\text { Changzhou }}$ & - Changzhou North \\
\hline Zhenjiang City & $\begin{array}{l}\text { - } \text { Danyang } \\
\text { - } \text { Dantu } \\
\text { - } \text { Zhenjiang } \\
\text { Baohuashan } \\
\end{array}$ & $\begin{array}{l}\text { - Danyang North } \\
\text { - } \quad \text { Zhenjiang West }\end{array}$ \\
\hline Nanjing City & - $\quad \underline{\text { Xianlin }}$ & - Nanjing South \\
\hline
\end{tabular}

Table 4. Stations along the Shanghai-Hangzhou corridor.

\begin{tabular}{|c|c|c|}
\hline City/Municipality & Huhang Line Stations & Hukun Line Stations \\
\hline $\begin{array}{l}\text { Shanghai } \\
\text { Municipality }\end{array}$ & $\begin{array}{l}\text { - Shanghai Hongqiao } \\
\text { - Songjiang South } \\
\text { - Jinshan North }\end{array}$ & - Shanghai Hongqiao \\
\hline Jiaxing City & $\begin{array}{ll}\text { - } & \text { Jiashan South } \\
\text { - } & \text { Jiaxing South } \\
\text { - } & \text { Tongxiang } \\
\text { - } & \text { Haining West }\end{array}$ & - Jiaxing South \\
\hline Hangzhou City & $\begin{array}{l}\text { - } \quad \text { Yuhang South } \\
\text { - Hangzhou East }\end{array}$ & - Hangzhou East \\
\hline
\end{tabular}

\section{Efficiency Impacts of HSR Lines}

This section focuses on assessing the transportation efficiency impacts of HSR lines, especially Huning Line and Huhang Line. Both Huning Line and Huhang Line will generate significant transportation and non-transportation impacts, as summarized below.

\subsection{Transportation-Related Impacts}

The transportation-related impacts of HSR projects are multifold. Below are some highlights.

\subsubsection{Reduced Travel Times}

The Huning rail line will bring travel time savings and an improved accessibility to those metropolitan areas and cities affected: Shanghai, Suzhou, Wuxi, Changzhou, Zhenjiang, and Nanjing metropolitan areas. Compared to conventional train, the HSR saves about 70 minutes of one-way travel time. Even compared to multiple unit train (MUT) (D-series HSR train), G-series HSR train still saves about 40 minutes of one-way travel time.

The Huhang Line will also achieve one-way travel time savings of 30 minutes (compared to multiple Unit train) and 50 minutes (compared to conventional train).

\subsubsection{Improved Accessibility}

This paper calculates the HSR-related economic potentials of the key YRD cities using the latest train schedules. See Tables 5 and $\mathbf{6}$ for details. Two scenarios are assumed: Fast travel time scenario with the high speed rail technology assumed; and the slowest travel time scenario with the conventional rail technology assumed. This calculation confirms the findings of [27] that the core areas of the YRD Megaregion (Suzhou, Wuxi, Changzhou, and Shanghai) on the Jiangsu Province side reap more benefits from the HSR development than the relatively

Table 5. HSR-related economic potentials of the key YRD cities (fastest travel time assumed).

\begin{tabular}{cccc}
\hline City & $\begin{array}{c}\text { GDP (Billion } \\
\text { Yuans) }\end{array}$ & $\begin{array}{c}\text { Economic } \\
\text { Potential (EP) }\end{array}$ & $\begin{array}{c}\text { Ranks of EP in } \\
\text { Descending Order }\end{array}$ \\
\hline Suzhou & 774 & 307.95 & 1 \\
Wuxi & 499.2 & 276.08 & 2 \\
Shanghai & 1490.1 & 214.36 & 3 \\
Changzhou & 251.9 & 171.50 & 4 \\
Jiaxing & 191.8 & 129.46 & 5 \\
Hangzhou & 509.9 & 128.08 & 6 \\
Zhenjiang & 167.2 & 126.59 & 7 \\
Nanjing & 423 & 122.03 & 8 \\
Shaoxing & 237.5 & 85.49 & 9 \\
Ningbo & 421.5 & 49.89 & 10 \\
Taizhou & 202.5 & 36.57 & 11 \\
\hline
\end{tabular}

Source: [28].

Table 6. HSR-related economic potentials of the key YRD cities (slowest travel time assumed).

\begin{tabular}{cccc}
\hline City & $\begin{array}{c}\text { GDP } \\
\text { (Billion Yuans) }\end{array}$ & $\begin{array}{c}\text { Economic } \\
\text { Potential (EP) }\end{array}$ & Ranks of EP \\
\hline Suzhou & 774 & 87.67 & 1 \\
Wuxi & 499.2 & 85.70 & 2 \\
Changzhou & 251.9 & 60.15 & 3 \\
Shanghai & 1490.1 & 55.90 & 4 \\
Jiaxing & 191.8 & 35.27 & 5 \\
Zhenjiang & 167.2 & 32.91 & 6 \\
Ningbo & 421.5 & 31.25 & 7 \\
Taizhou & 202.5 & 29.99 & 8 \\
Nanjing & 423 & 29.73 & 9 \\
Shaoxing & 237.5 & 29.01 & 10 \\
Hangzhou & 509.9 & 27.28 & 11 \\
\hline
\end{tabular}

Source: [28]. 
outlying areas on the Zhejiang Province side.

\subsubsection{Enhanced Corridor Transportation Capacity}

In addition to their significant travel time savings, both Huning and Huhang lines will have separate passenger operations (using new lines) from freight operations (using existing lines), thus greatly enhancing the transportation capacity of both corridors, relieving overcrowding and delays caused by sharing rail rights-of-ways.

\subsubsection{Improved Intermodal Connection}

The HSR lines will help improve intermodal connection in many hub cities, especially Shanghai, Nanjing, Hangzhou, Suzhou, and Wuxi. Take Shanghai for example. As one of the eastern termini of the Huning Line, Shanghai Hongqiao Airport Terminal 2 has become a multimodal interchange station among four high speed rail lines (Beijing-Shanghai PDL, Shanghai-Hangzhou Intercity HSR Line, Shanghai-Wuhan-Chengdu PDL, Hukun PDL), two Shanghai Metro subway lines (Line 2 and Line 10), and Hongqiao International Airport.

\subsection{Non-Transportation-Related Impacts}

The non-transportation-related impacts are described in this section.

\subsubsection{Strengthened Nodal Transit-Oriented Development (TOD)}

The Huning Line traverses the entire Southern Jiangsu Province, which is at the core of the Shanghai Megaregion (the largest and most developed one in China). Those cities and areas located in the immediate vicinity of HSR train stations are primary beneficiaries of this new transportation alternative.

In Hangzhou, the City East New Town is the HSR terminal area. At present, this area primarily serves as a transportation terminal. Its other functions in tourism, logistics, business and entertainment have not been fully played yet. Due to the opening of HSR, Hangzhou and Shanghai have formed a one-hour transportation circle. Many tourists may tour Hangzhou during daytime and stay in Shanghai at night. Therefore, Hangzhou's hotel business may be negatively impacted.

\subsubsection{Reinforced Corridor Spillover Effects}

Table 7 shows the economic strength and density of the cities traversed by HSR lines. Economic strength and economic density (preferred indicator) are measured by total 2009 GDP, and 2009 GDP/km, respectively. From this table, it can clearly be seen that: 1) Nanjing-Hangzhou (Ninghang) Line, Shanghai-Hangzhou (Huhang) Line, and Shanghai-Nanjing (Huning) Line encompass the triangular-shaped area with the strongest economy. The cities traversed by these three lines had the highest total GDPs in 2009; 2) Shanghai-Hangzhou (Huhang) Line and Shanghai-Nanjing (Huning) Line are associated with the highest economic densities. Therefore, these two lines traverse the most important transportation corridors and can be regarded as Tier-1 rail corridors. Due to its much shorter length, the Huhang Line had a slightly higher economic density that the Huning Line. Along the Huning Line, the eastern cities (Suzhou, Wuxi, and Changzhou) are relatively more developed than the western cities (Nanjing and Zhenjiang); 3) Based on their economic densities, Changzhou-Suzhou-Jiaxing (Changsujia) Line, Nanjing-Hangzhou (Ninghang) Line, Nanjing-Wuhu (Ningwu) Line, and Xiaoshan-Ningbo (Xiaoyong) Line can be regarded as Tier-2 rail corridors. The rest lines are Tier- 3 corridors.

According to [29], the industries in Shanghai are capital-intensive, and the others in Zhejiang and Jiangsu provinces are labor-intensive. In expanding their production capacity, many of Shanghai's plants contract out the labor-intensive production processes to plants in other cities, while retaining its capital-intensive industries. Therefore, those low-end labor-intensive industries are more likely to be dispersed, whereas high-end capitalintensive industries will continue to be centralized at growth pole cities like Shanghai. Economic polarization and dispersion coexists in the YRD Megaregion.

In summary, due to the better intercity linkage provided by the HSR, the nodal TOD will eventually be turned into the linear Transit-Oriented Corridor (TOC) along the HSR corridors. TOC is the "pearl necklacelike" linear land development chaining all nodal TODs together, reflecting corridor spillover effects. The polycentric, linear TOCs along the rail corridors are destined to become the ideal urban spatial structures in China due to the pole-axis dispersion development pattern [30].

\subsubsection{Resource Optimal Distribution}

By decreasing the travel times between cities in the region, the new trains make it practical for companies to spread out their facilities into locations that are most suitable for each type of operation. This means that while a company may need to keep its sales offices in Shanghai for proximity to its customers, it can easily set up production in a lower wage area such as Kunshan which will be less than 30 minutes away, or establish research and development facilities in industrial parks in Suzhou or Wuxi where it can enjoy favorable tax conditions and lower land costs. Also, by placing the cities of the Yangtze River Delta within an easy reach of each other, the new rail system may make it easier to relocate existing management into emerging cities, thus relieving some of the cost pressures on companies operating in Shanghai and other urban center. People working in Shanghai can also buy houses and live in other neighboring cities. 
Table 7. Economic strength and density of the cities traversed by HSR lines.

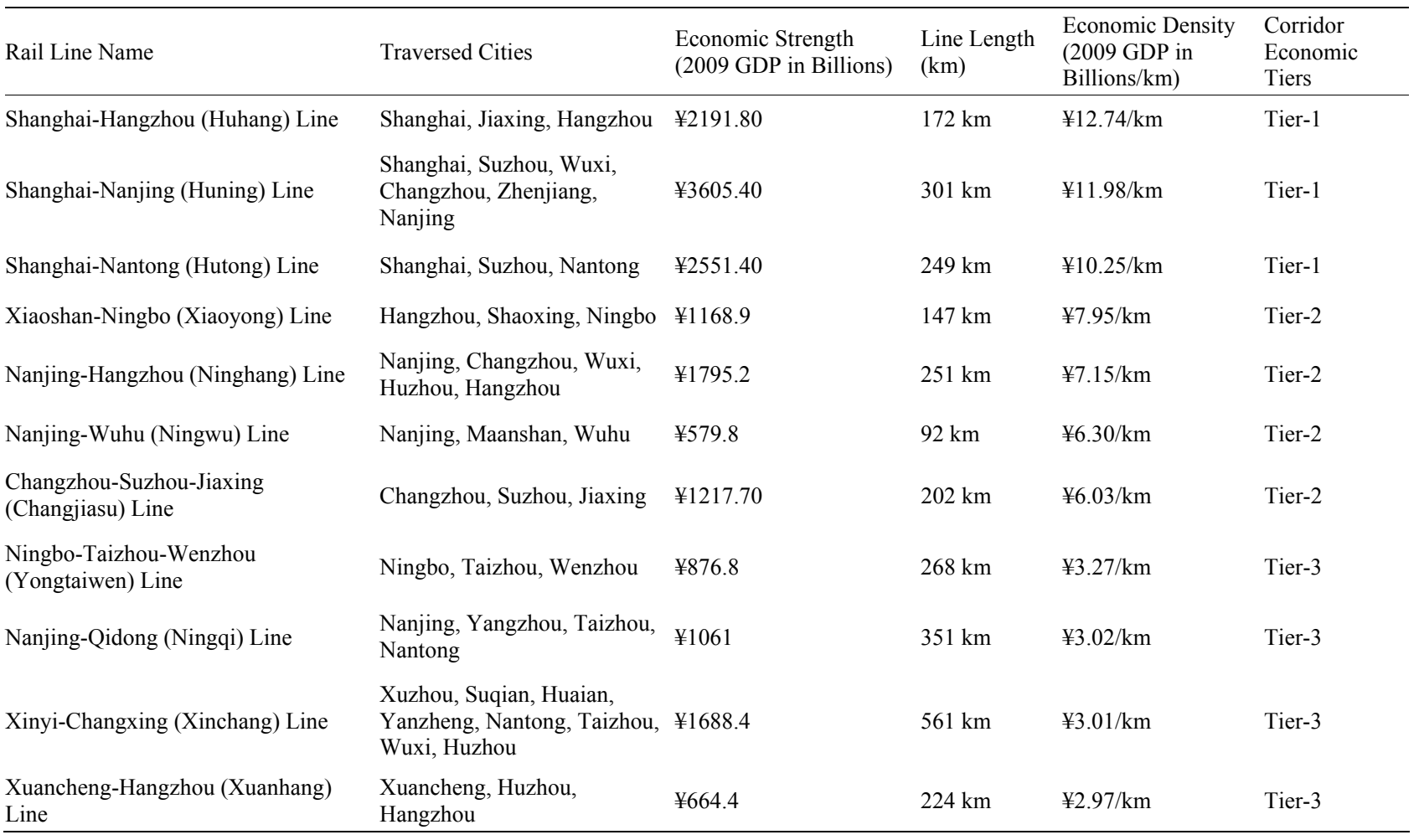

Source: From each city's published 2009 statistical data.

\section{Equity Issues of HSR Lines}

As indicated above, the efficiency impacts of HSR lines are so obvious in the YRD Megaregion. However, its equity issues are often raised.

Following the modeling approach proposed in Section 3 , the city-level connectivity indices in the YRD Region can be calculated and shown in Table 8 .

Table 8 clearly indicates that:

First, the more connected cities are Shanghai and those cities along the Huning Corridor and Huhang Corridor.

Second, the less connected cities are those cities in the north of Yangtze River in Jiangsu Province, and the east/ south of Zhejiang Province.

Third, the future HSR plans in the YRD region will aggravate the regional inequalities while lifting the overall economic development levels. The HSR-induced economic and non-economic benefits are apparently unevenly distributed across the YRD cities.

\section{Conclusions}

Through this empirical analysis, it can be concluded that HSR lines (PDL trunk lines and intercity lines) will generate significant transportation and non-transportation impacts.

With respect to transportation impacts, HSR lines will dramatically reduce travel times, improve accessibility, enhance corridor transportation capacity, strengthen intermodal connection, and realize other benefits.

In terms of its non-transportation impacts, HSR lines can effectively strengthen nodal transit-oriented development (TOD), reinforce corridor spillover effects, optimally distribute regional resources, and others.

In the meantime, it should also be recognized that HSR lines will also generate inequity issues. Geographically, the existing HSR plans, if fully implemented, will only worsen geographic equity, which makes the rich cities richer and the poor cities poorer, even though the overall regional economic development levels will be lifted. The polarization trends seem evident amid the HSR plan implementation.

The proposed PANS model helps conduct this study. The pole-tiers and axis-tiers are highly correlated. Some low-end economic activities and resources may be dispersed and trickled down from higher-tier cities to lowertier cities. But, the reverse concentration and agglomeration processes may even be stronger, making Shanghai the more dominant central city in the YRD Region.

\section{Acknowledgements}

This author greatly appreciates the data support provided by Professor Haixiao Pan, Department of Urban Planning, Tongji University, China. The potential remaining errors 
Table 8. City-level connectivity indices in the YRD region.

\begin{tabular}{|c|c|c|c|}
\hline City Tier & City Name & Connected Axis Tier & CI \\
\hline Tier-1 City & Shanghai & $\begin{array}{l}5 \text { Tier-1 Axis(es): Jinghu PDL, Hukun PDL, Huning Intercity HSR Line, } \\
\text { Huhang Intercity HSR Line, Hutong Rail Line; } \\
0 \text { Tier-2 Axis(es): N/A; } \\
0 \text { Tier-3 Axis(es): N/A; }\end{array}$ & 25 \\
\hline Tier-3 City & Nanjing & $\begin{array}{l}2 \text { Tier-1 Axis(es): Jinghu PDL, Huning Intercity HSR Line; } \\
2 \text { Tier-2 Axis(es): Ninghang Intercity HSR Line, Ningwu Rail Line; } \\
1 \text { Tier-3 Axis(es): Ningqi Rail Line. }\end{array}$ & 17 \\
\hline Tier-3 City & Hangzhou & $\begin{array}{l}2 \text { Tier-1 Axis(es): Hukun PDL, Huhang Intercity HSR Line; } \\
1 \text { Tier-2 Axis(es): Xiaoyong Intercity HSR Line; } \\
1 \text { Tier-3 Axis(es): Xuanhang Rail Line }\end{array}$ & 14 \\
\hline Tier-2 City & Suzhou & $\begin{array}{l}2 \text { Tier-1 Axis(es): Jinghu PDL, Huning Intercity HSR Line; } \\
1 \text { Tier-2 Axis(es): Changsujia Rail Line; } \\
0 \text { Tier-3 Axis(es): N/A. }\end{array}$ & 13 \\
\hline Tier-4 City & Jiaxing & $\begin{array}{l}2 \text { Tier-1 Axis(es): Hukun PDL, Huhang Intercity HSR Line; } \\
1 \text { Tier-2 Axis(es): Changsujia Rail Line; } \\
0 \text { Tier-3 Axis(es): N/A. }\end{array}$ & 13 \\
\hline Tier-3 City & Changzhou & $\begin{array}{l}2 \text { Tier-1 Axis(es): Jinghu PDL, Huning Intercity HSR Line; } \\
1 \text { Tier-2 Axis(es): Changsujia Rail Line; } \\
0 \text { Tier-3 Axis(es): N/A. }\end{array}$ & 13 \\
\hline Tier-2 City & Wuxi & $\begin{array}{l}2 \text { Tier-1 Axis(es): Jinghu PDL, Huning Intercity HSR Line; } \\
0 \text { Tier-2 Axis(es): N/A; } \\
1 \text { Tier-3 Axis(es): Xinchang Line. }\end{array}$ & 11 \\
\hline Tier-3 City & Zhenjiang & $\begin{array}{l}2 \text { Tier-1 Axis(es): Jinghu PDL, Huning Intercity HSR Line; } \\
0 \text { Tier-2 Axis(es): N/A } \\
0 \text { Tier-3 Axis(es): N/A }\end{array}$ & 10 \\
\hline Tier-4 City & Nantong & $\begin{array}{l}1 \text { Tier-1 Axis(es): Hutong Rail Line; } \\
0 \text { Tier-2 Axis(es): N/A; } \\
1 \text { Tier-3 Axis(es): Ningqi Rail Line. }\end{array}$ & 6 \\
\hline Tier-3 City & Ningbo & $\begin{array}{l}0 \text { Tier-1 Axis(es): N/A; } \\
1 \text { Tier-2 Axis(es): Xiaoyong Intercity HSR Line; } \\
1 \text { Tier-3 Axis(es): Yongtaiwen Rail Line }\end{array}$ & 4 \\
\hline Tier-4 City & Huzhou & $\begin{array}{l}0 \text { Tier-1 Axis(es): N/A; } \\
1 \text { Tier-2 Axis(es): Ninghang Intercity HSR Line; } \\
1 \text { Tier-3 Axis(es): Xuanhang Rail Line. }\end{array}$ & 4 \\
\hline Tier-4 City & Shaoxing & $\begin{array}{l}0 \text { Tier-1 Axis(es): N/A; } \\
1 \text { Tier-2 Axis(es): Xiaoyong Intercity HSR Line; } \\
0 \text { Tier-3 Axis(es): N/A }\end{array}$ & 3 \\
\hline Tier-4 City & Yangzhou & $\begin{array}{l}0 \text { Tier-1 Axis(es): N/A; } \\
0 \text { Tier-2 Axis(es): N/A; } \\
1 \text { Tier-3 Axis(es): Ningqi Rail Line }\end{array}$ & 1 \\
\hline Tier-4 City & Taizhou in Jiangsu & $\begin{array}{l}0 \text { Tier-1 Axis(es): N/A; } \\
0 \text { Tier-2 Axis(es): N/A; } \\
1 \text { Tier-3 Axis(es): Ningqi Rail Line }\end{array}$ & 1 \\
\hline Tier-4 City & Taizhou in Zhejiang & $\begin{array}{l}0 \text { Tier-1 Axis(es): N/A; } \\
0 \text { Tier-2 Axis(es): N/A; } \\
1 \text { Tier-3 Axis(es): Ningtaiwen Rail Line. }\end{array}$ & 1 \\
\hline Tier-4 City & Zhoushan & $\begin{array}{l}0 \text { Tier-1 } \operatorname{Axis}(\mathrm{es}): \mathrm{N} / \mathrm{A} \\
0 \text { Tier-2 Axis(es): N/A; } \\
0 \text { Tier-3 Axis(es): N/A. }\end{array}$ & 0 \\
\hline
\end{tabular}

Notes: $\mathrm{CI}=5 *$ Number of Connected Tier-1 Axis(es) $+3 *$ Number of Connected Tier-2 Axis(es) $+1 *$ Number of Connected Tier-3 Axis(es).

of this paper are mine.

\section{REFERENCES}

[1] http://news.21cn.com/domestic/yaowen/2010/03/13/7402 813.shtml

[2] J. Campos and G. de Rus, "Some Stylized Facts about
High-Speed Rail: A Review of HSR Experiences around the World," Transport Policy, Vol. 16, No. 1, 2009, pp. 19-28. doi:10.1016/j.tranpol.2009.02.008

[3] R. Knowles, J. Shaw and I. Docherty, "Transport Geographies: Mobilities, Flows and Spaces," Wiley-Blackwell, Malden, 2008.

[4] M. Givoni, "Development and Impact of the Modern High- 
Speed Train: A Review," Transport Reviews, Vol. 26, No. 5, 2006, pp. 593-611. doi:10.1080/01441640600589319

[5] COST 318, "Interaction between High Speed Rail and Air Passenger Transport," Directorate General of Transport, European Commission, 1998.

[6] J. Gutierrez, R. Gonzalez and G. Gomez, "The European High-Speed Train Network: Predicted Effects on Accessibility Patterns," Journal of Transport Geography, Vol. 4, No. 4, 1996, pp. 227-238. doi:10.1016/S0966-6923(96)00033-6

[7] J. Gutierrez, "Location, Economic Potential and Daily Accessibility: An Analysis of the Accessibility Impact of the High-Speed Line Madrid-Barcelona-French Border," Journal of Transport Geography, Vol. 9, No. 4, 2001, pp. 229-242. doi:10.1016/S0966-6923(01)00017-5

[8] M. Diao and Y. Zhu, "High Speed Rail Network, Accessibility and Regional Development in China," 6th Annual Conference of the International Association for China Planning, Wuhan, 18 June 2012.

[9] R.-Q. Yao, "Researching the Influence toward Hangzhou of the High Speed Railway of Shanghai to Hangzhou," Modern Urban Research, No. 6, 2010, pp. 16-24.

[10] B. Sands, "The Development Effects of High-Speed Rail Stations and Implications for California," Built Environment, Vol. 19, No. 3-4, 1993, pp. 257-284.

[11] H. Priemus, P. Nijkamp and D. Banister, "Mobility and Spatial Dynamics: An Uneasy Relationship," Journal of Transport Geography, Vol. 9, No. 3, 2001, pp. 167-171. doi:10.1016/S0966-6923(01)00007-2

[12] A. Bonnafous, "The Regional Impact of the TGV," Transportation, Vol. 14, No. 2, 1987, pp. 127-137. doi:10.1007/BF00837589

[13] K. Spiekermann and M. Wegener, "The Shrinking Continent: New Time-Space Maps of Europe," Environment and Planning B, Vol. 21, No. 6, 1994, pp. 653-673. doi:10.1068/b210653

[14] R. Vickerman, "High-Speed Rail in Europe: Experience and Issues for Future Development," The Annals of Regional Science, Vol. 31, No. 1, 1997, pp. 21-38. doi:10.1007/s001680050037

[15] R. Cervero and M. Bernick, "High-Speed Rail and Development of California's Central Valley: Comparative Lessons and Public Policy Considerations," Institute of Urban and Regional Development, University of California, Berkeley, 1996. http://iurd.berkeley.edu/sites/default/files/wp/675.pdf

[16] D. Banister and Y. Berechman, "Transport Investment and the Promotion of Economic Growth," Journal of Transport Geography, Vol. 9, No. 3, 2001, pp. 209-218. doi:10.1016/S0966-6923(01)00013-8

[17] U. Blum, K. E. Haynes and C. Karlsson, "The Regional and Urban Effects of High-Speed Trains," The Annals of Regional Science, Vol. 31, No. 1, 1997, pp. 1-20. doi:10.1007/s001680050036

[18] D. Lu, "An Analysis of Spatial Structure and Optimal Regional Development," Scientia Geographica Sinica, Vol. 56, No. 2, 2001, pp. 127-135.

[19] D. Lu, "Formation and Dynamics of the 'Pole-Axis' Spatial System," Scientia Geographica Sinica, Vol. 22, No. 1, 2002, pp. 1-6.

[20] D. Lu, "Objective and Framework for Territorial Development in China," Chinese Geographical Science, Vol. 19, No. 3, 2009, pp. 195-202. doi:10.1007/s11769-009-0195-9

[21] W. Christaller, "Die Zentralen Orte in Suddeutschland," Gustav Fischer, Jena, 1933. Translated (in part), by C. W. Baskin, as Central Places in Southern Germany, Prentice Hall, Upper Saddle River, 1966.

[22] F. Perroux, "Economic Space: Theory and Applications," Quarterly Journal of Economics, Vol. 64, No. 1, 1950, pp. 89-104. doi:10.2307/1881960

[23] A. O. Hirschman, "The Strategy of Economic Development," Yale University Press, New Haven, 1958.

[24] V. R. Vuchic, "Urban Transit Systems and Technology," John Wiley \& Sons, Inc., Hoboken, 2007. doi:10.1002/9780470168066

[25] http://www.china-mor.gov.cn/dzdt/tlyyxl_small.html

[26] http://www.hudong.com/categorypage/show/\%E4\%B8\% $\mathrm{AD} \% \mathrm{E} 5 \% 9 \mathrm{~B} \% \mathrm{BD} \% \mathrm{E} 9 \% 93 \% 81 \% \mathrm{E} 8 \% \mathrm{~B} 7 \% \mathrm{AF} \% \mathrm{E} 7 \% \mathrm{~B}$ $\mathrm{A} \% \mathrm{BF} /$

[27] Y.-L. Huan and C.-L. Xu, "Study on the Influence of Traffic Integration of Yangtze River Delta on the Potential of Local Economic Development (in Chinese)," East China Economic Management, Vo1. 25, No. 8, 2011, pp. 10-11.

[28] http://chaxun.shike.org.cn/FindResult.asp

[29] J. Yang, "Spatial Planning in Asia," In: C. L. Ross, Ed., Megaregions: Planning for Global Competitiveness, Island Press, Washington DC, 2009, pp. 35-52.

[30] Z. Sun and Y. Yang, "Inter-City Rail Transit and Urban Development (in Chinese)," Modern Urban Research, No. 12, 2005, pp. 38-42. 